\title{
Educação ambiental e sistemas de ensino: estudo de caso em uma escola pública do município de Lauro Müller (SC)
}

\author{
Environmental education and education system: case study in a public \\ school in the municipality of Lauro Müller (SC)
}

\section{Nilzo Ivo Ladwig '; Jaqueline Cristiane Pandini"'; Viviane Kraieski de Assunção"I}

\begin{abstract}
RESUMO
A obrigatoriedade da Educação Ambiental - EA está garantida na educação escolar por meio da legislação, que ressalta a importância da interdisciplinaridade. Este artigo apresenta os resultados de uma pesquisa, caracterizada como um estudo de caso, sobre concepções e práticas de EA no sexto ano do Ensino Fundamental de uma escola pública do município de Lauro Müller (SC). No ano em que a pesquisa foi realizada, o sistema apostilado passou a ser utilizado em todas as disciplinas do sexto ano das escolas municipais. Por meio da investigação, apresentam-se aqui, (1) as dificuldades e potencialidades apontadas pelos professores que lecionam nesta série para a realização da EA; (2) a presença de conteúdos de EA nas apostilas, por meio da análise dos textos e exercícios que as compõem. Conclui-se que os professores necessitam de formação continuada em EA que possibilite a construção de alternativas de forma a integrar as áreas de conhecimento.
\end{abstract}

Palavras-chave: Interdisciplinaridade; Sistema de Ensino; Material didático

\section{ABSTRACT}

The obligation of Environmental Education - EE is guaranteed in school education through legislation, which emphasizes the importance of interdisciplinarity. This article presents the results of a research, characterized as a case study, about conceptions and practices of EE in the sixth year of Basic Education in a public school in the municipality of Lauro Müller (SC). In the year the research was carried out, the workbook was used in all courses of the 6th grade of municipal schools. Through the research, we present here (1) the difficulties and potentialities pointed out by the teachers who teach in this series for EA; (2) the presence of EE contents in the workbooks, through the analysis of texts and exercises that compose them. It is concluded that teachers need continuous training in EE that allows the construction of alternatives in order to integrate the areas of knowledge.

Keywords: Interdisciplinarity; Education system; Teaching material

\footnotetext{
Doutor em Engenharia. Professor do Programa de Pós-Graduação em Ciências Ambientais da Universidade do Extremo Sul Catarinense e da Universidade do Sul de Santa Catarina. ladwig@unesc.net. (1)

" Licenciada em Geografia. Docente da E.E.F. Lucas Bez Batti e Docente da Escola Municipal Lígia Chaves Cabral. jaquepandini@gmail.com.

III Doutora em Antropologia Social. Professora do Programa de Pós-Graduação em Ciências Ambientais da Universidade do Extremo Sul Catarinense.vka@unesc.net. (1)
} 


\section{INTRODUÇÃO}

A EA está garantida na educação formal por meio da lei, nos níveis federal, estadual e municipal, que destaca sua importância e que deve ser praticada por todas as disciplinas e nas diferentes modalidades de ensino. Dessa forma, é fundamental que as escolas incluam a EA como tema transversal, já que a lei federal salienta em seu artigo $10^{\circ}$, inciso $1^{\circ}$, que a EA não pode ser uma disciplina específica, mas é um tema que deve permear toda a prática educativa. Ela deve ser contemplada nos mais diversos componentes curriculares, uma vez que é elemento imprescindível para a formação da consciência ambiental (BRASIL, 1999).

Um dos princípios que norteiam a EA, de acordo com a legislação brasileira e os documentos oriundos das conferências internacionais, como Tbilisi e Rio 92, é a interdisciplinaridade, compreendida como meio de articular diferentes áreas e formas de conhecimento (FAZENDA, 1999), a fim de superar a compartimentalização dos saberes e proporcionar uma visão da complexidade (MORIN, 2002) da realidade socioambiental.

Para a realização da interdisciplinaridade, é preciso também superar a visão naturalista, presente em muitas concepções e práticas de EA. Deste modo, mais do que a formação de conhecimentos sobre a natureza a partir de uma concepção meramente biológica ou física, a EA deve partir de uma visão holística do meio ambiente, compreendendo-o em suas múltiplas dimensões (naturais, sociais, culturais, econômicas e políticas) e seguindo uma abordagem integradora entre o ser humano e o meio (CARVALHO, 2006; DIAS, 2004). Deste modo, a EA pode contribuir para a formação de uma nova ética e visão de mundo (BOFF, 2004; GRÜN, 1996), que contribua para a transformação humana e, consequentemente, a superação dos problemas socioambientais. 
Além das mudanças exigidas pela legislação, como a inclusão da EA em todos os níveis de ensino, os processos de ensino-aprendizagem nas escolas também vêm passando por transformações, como a adoção dos denominados "sistemas de ensino", por meio da utilização de apostilas. Este sistema surge a partir da parceira entre os setores públicos e privados e, neste sentido, mais do que a adoção dos materiais didáticos, representa "estratégia por meio da qual o setor privado amplia seu mercado, ao incidir sobre o espaço público na mesma medida em que o setor público transfere parcela de suas responsabilidades para com a educação à iniciativa privada" (ADRIÃO et al. 2009, p. 801).

A adoção do sistema apostilado na Educação Básica tem sido caracterizada por críticas e polêmicas. Como expõe Britto (2011), este material, produzido por empresas privadas, não passa por nenhum tipo de avaliação oficial, a exemplo do que acontece com os livros didáticos adquiridos pelo PNLD (Programa Nacional do Livro Didático) e pelo PNLEM (Programa Nacional do Livro Didático para o Ensino Médio), ambos do Governo Federal. Estudos indicam que estes materiais apostilados apresentam problemas conceituais e gráficos, "além da utilização de abordagens pedagógicas descontextualizadas e excessivamente esquemáticas, herdeiras da orientação para o vestibular que caracterizou o surgimento desse tipo de material" (BRITTO, 2011, p. 14).

Silva e Leite (2017, p. 18892) problematizam "que percepções positivas, em relação ao material apostilado podem estar, muitas vezes, atreladas a uma lógica mercadológica."O assédio dos grupos empresariais, que buscam expandir o campo de atuação nas redes municipais, promete melhorias na qualidade educacional que por vezes não se confirma, pois na maioria dos casos a participação dos professores neste processo decisório não acontece, prejudicando a avaliação da qualidade do material apostilado produzido.

De acordo com Geraldi (2002), ao se questionar o material didático, podese também problematizar o conceito de ensino que ele materializa. Ao analisa-lo, 
além de considerar a qualidade de textos e exercícios, torna-se necessário averiguar se o material apresenta questões ambientais e se existe a possibilidade de promover a EA, visto a crescente necessidade do mundo atual (PEREIRA; MARCOMIN, 2013).

Giacomini e Otto (2017) realizaram uma pesquisa em escolas da rede municipal de ensino de Florianópolis (SC), entre 2009 e 2012. Concluem que o uso da apostila em sala de aula pode auxiliar a organização do trabalho do professor e proporcionar uma possível uniformidade no tratamento dos conteúdos; por outro, bloqueia a autonomia do professor na elaboração de seu programa de trabalho e de sua organização curricular, além de direcionar o funcionamento da própria rede escolar.

Diante do que foi discutido e pautado pelos autores citados acima e considerando os resultados pesquisados por Bego (2019) que realizou pesquisa em uma rede municipal de ensino no interior de São Paulo que avaliou a implantação de sistema apostilado de ensino e o trabalho docente, os problemas e as decisões de uma rede escolar pública municipal. Concluiu que os professores da rede não participaram com direito à opinião e, sobretudo, com direito à interferência.

Seguindo as discussões destes e de demais autores, este artigo apresenta os resultados de uma pesquisar realizada em 2018, caracterizada como um estudo de caso, sobre as concepções e práticas de EA no sexto ano do ensino Fundamental de uma escola pública do município de Lauro Müller (SC). No ano em que a pesquisa foi realizada, o sistema apostilado passou a ser utilizado em todas as disciplinas do $6^{\circ}$ ano das escolas municipais. Por meio dos resultados da investigação, são apresentadas, aqui, (1) as dificuldades e potencialidades apontadas pelos professores que lecionam nesta série para a realização da EA; (2) a presença de conteúdos de EA nas apostilas, por meio da análise dos textos e exercícios que os compõem. 


\section{MATERIAIS E MÉTODOS}

\subsection{Lócus do estudo}

O município de Lauro Müller localiza-se na região sul do Estado de Santa Catarina (Figura 1), com uma população de 15.073 habitantes e com uma área territorial de 270,781 $\mathrm{Km}^{2}$ (IBGE, 2015).

\section{Figura 1- Localização do município de Lauro Müller}

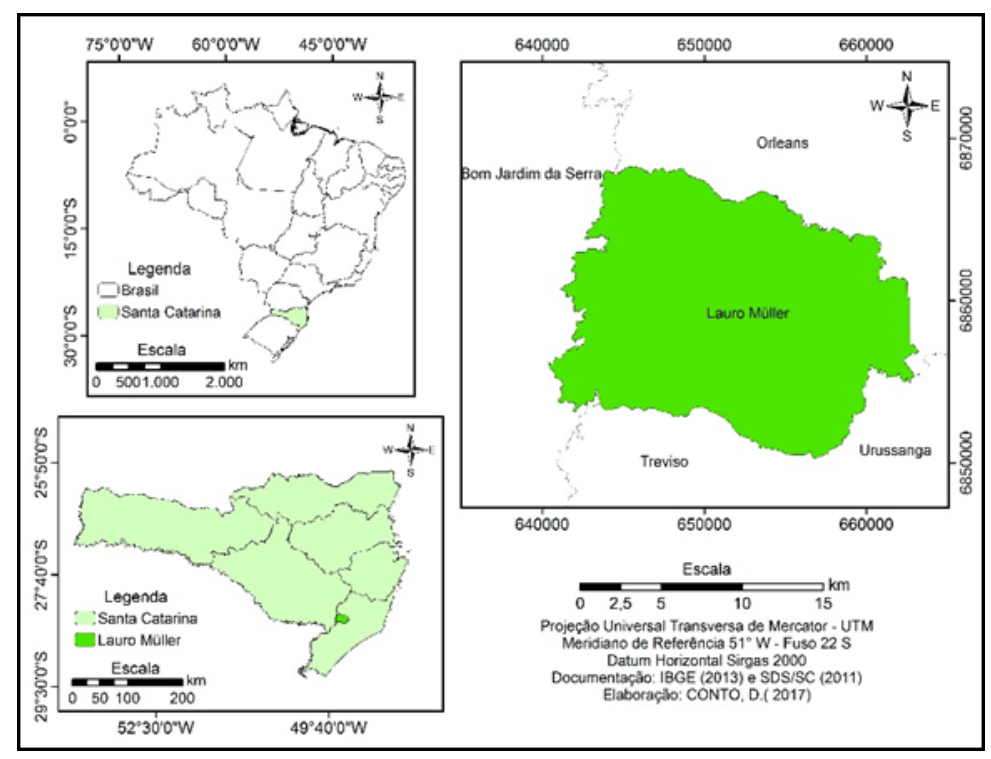

Fonte: Organização dos autores, 2018

A história do município de Lauro Müller está ligada à exploração de carvão na região sul do Brasil (SHEIBE, 1993; NASCIMENTO, 2004; LOPES, 2008), atividade que resiste na atualidade. No entanto, é importante ressaltar que o município também desenvolve outras atividades econômicas, como a agricultura, com destaque para os cultivos de cana de açúcar, uva e banana. A pecuária se desenvolve principalmente com os rebanhos de bovinos, aves e suínos. Outro setor da economia que ganha destaque é o comércio e a prestação de serviços (SEBRAE/SC, 2010).

O ensino no município de Lauro Müller está pautado em duas legislações: a LDB N 9.394/96 (Lei de Diretrizes e Base da Educação Nacional) e a Lei Orgânica 
Municipal que propõe ensino gratuito e de qualidade a todos os munícipes (PPP, 2015). A rede municipal de ensino segue a Proposta Curricular do Estado de Santa Catarina, cuja organização pedagógica está alicerçada na teoria históricocultural (PPP, 2015).

É importante destacar que o ensino municipal apresenta-se fragmentado por disciplinas, sendo o oposto da atual Proposta Curricular do Estado de Santa Catarina, que trabalha com a formação integral e discute a necessidade de superação da fragmentação da educação por meio das disciplinas, agrupadas nas seguintes áreas de conhecimento: linguagem (artes, educação física, língua portuguesa, língua materna e língua estrangeira), ciências humanas (história, geografia, sociologia, filosofia e ensino religioso) e ciências da natureza e matemática (biologia, química, física e matemática) (SANTA CATARINA, 2014).

A lei estadual $n^{\circ} 13.558$, de 17 de novembro de 2005, que regulamenta a EA, vem reforçar as obrigações e orientações instituídas pela lei federal. Destacase o artigo $2^{\circ}$, parágrafo único, que aponta que a responsabilidade ambiental não é só do poder público, ou da escola, mas também se estende à família, à comunidade e aos movimentos sociais, para que possam contribuir na formação da cidadania. A lei ressalta que a capacitação é um dever do Estado, que deve garantir cursos de aperfeiçoamento ao corpo docente, administrativo e à comunidade (SANTA CATARINA, 2005). Já a lei $n^{\circ} 1.507 / 2008$, do município de Lauro Müller, também garante a obrigatoriedade da EA na rede municipal de ensino, em todas as áreas do conhecimento, durante o ano letivo, cumprindo o currículo escolar (LAURO MÜLLER, 2008).

No município de Lauro Müller, a rede municipal de ensino conta com quatro unidades escolares que oferecem o ensino fundamental anos iniciais e anos finais. Essas unidades de ensino possuem um total de 967 alunos e 84 professores, sendo que há professores que atuam nas duas modalidades do fundamental, considerando as quatro unidades. Essas unidades escolares em questão apresentam seis turmas de $6^{\circ}$ ano do ensino fundamental anos finais, com um total de 139 alunos e 22 professores, incluindo uma das pesquisadoras e desconsiderando os profissionais de ensino religioso e educação física, pois os mesmos não possuem suas disciplinas inclusas no material didático. 
A Escola Municipal Lígia Chaves Cabral, lócus do estudo, foi fundada em 1955. A escola está localizada no bairro Itanema. No contexto histórico, pode-se mencionar que a escola surge em meio à exploração carbonífera. Com o passar do tempo, as famílias buscaram outras atividades, e hoje se destacam como trabalhadores autônomos, diaristas e agricultores. No contexto social, há uma grande carência de estruturas e projetos que incentivem o lazer e os esportes na comunidade (PPP, 2015).

Atualmente, a unidade escolar oferece o ensino fundamental anos iniciais e anos finais, de $1^{\circ}$ ao $9^{\circ}$ ano, além de manter a direção do Pré-escolar Reino Infantil. No ensino fundamental, conta com um total de 145 alunos entre os períodos, matutino e vespertino. Para atender esse total de alunos do ensino fundamental na unidade escolar, existe um quadro de 17 professores (PPP, 2015). A pesquisa foi realizada no $6^{\circ}$ ano do ensino fundamental, que conta com 15 alunos e sete professores.

\subsection{Procedimentos Metodológicos}

\subsubsection{Entrevistas com professores}

A fim de identificar as dificuldades e potencialidades da prática pedagógica da escola e dos professores relacionadas às ações de EA, foi realizada uma pesquisa exploratória (GIL, 1999), por meio de dois instrumentos. O primeiro foi um questionário com perguntas abertas, fechadas e dependentes (GIL, 1999), que foi respondido por cada professor das disciplinas que compõe as apostilas do $6^{\circ}$ ano do ensino fundamental dos anos finais. Este questionário tinha como objetivo conhecer o perfil do grupo de docente da unidade escolar (formação, experiência profissional e áreas de atuação). O segundo instrumento foi um roteiro de entrevista focalizada, que foi aplicado por meio de um grupo focal, no qual todos os professores estavam reunidos e discutiram a importância da EA, da 
interdisciplinaridade, além de socializarem suas experiências, as suas ações ou anseios em relação à EA. O professor de geografia contribuiu com a pesquisa de maneira diferenciada, por meio da observação participante natural (GIL, 1999), visto que a profissional em questão também é uma das pesquisadoras.

Do grupo de professores que atuam no $6^{\circ}$ ano do ensino fundamental anos finais, participaram da entrevista quatro professores, contemplando as disciplinas de artes, ciências, história, língua portuguesa, língua inglesa e matemática. Não participaram da entrevista os professores que lecionam as disciplinas de educação física e de ensino religioso, pois as disciplinas em questão não se encontram no sistema apostilado, visto que o foco da pesquisa é compreender a prática da EA por meio deste material didático; nesse sentido, foi decidido previamente não envolver na pesquisa essas disciplinas.

\subsubsection{Análise das apostilas}

No anseio de atender o segundo objetivo da pesquisa, que era compreendido pela análise das apostilas distribuídas pela prefeitura no que diz respeito ao conteúdo que versa sobre a EA no $6^{\circ}$ ano do ensino fundamental dos anos finais, foram utilizadas as técnicas de análise de conteúdo de Bardin (2004, p. 33), que “(...) aparece como um conjunto de técnicas de análise das comunicações, que utiliza procedimentos sistemáticos e objetivos de descrição do conteúdo das mensagens", seguindo o desenvolvimento das seguintes etapas: a pré-análise, a exploração do material, o tratamento dos resultados e a interpretação.

O principal objetivo da análise do material didático foi o de reconhecimento de conteúdosou exercícios que remetem à EA, buscando responder às seguintes questões: A apostila apresenta a EA em todas as disciplinas? Em todos os seus segmentos? No conteúdo das apostilas, podemos identificar a interdisciplinaridade? 
No período de exploração do material, foi analisado o conteúdo da apostila, nos quatro bimestres, dentre todas as disciplinas que compõe o $6^{\circ}$ ano do ensino fundamental dos anos finais. Percebeu-se que o material didático é estruturado da seguinte forma: textos, textos complementares e exercícios. É importante ressaltar que há uma diferença na quantidade desses textos e exercícios entre as disciplinas, apesar de apresentarem a mesma estrutura organizativa.

Para realizar a análise de conteúdo das apostilas, foram utilizados os critérios selecionados por Pereira e Marcomim (2013, p. 170), procurando perceber se os textos e exercícios (1) abordam critérios ambientais; (2) tratam de problemas socioambientais (ou seja, aqueles decorrentes da ação antrópica); (3) incluem o ser humano no meio ambiente; (4) atendem à diversidade natural, cultural e regional; (5) empregam expressões como respeito, ética, cidadania, comprometimento, responsabilidade e amor; (6) empregam tais expressões no âmbito de formação de valores; (7) empregam elementos que simbolizam consciência, respeito, ética, cidadania, comprometimento, responsabilidade e amor; (8) mencionam os termos educação ambiental, sustentabilidade, desenvolvimento sustentável, sociedade sustentável ou algum outro semelhante; e (9) tratam de aspectos relativos aos objetivos e aos princípios da EA. Dentre as fontes utilizadas na formulação destes critérios, estão os princípios estabelecidos pela Conferência Intergovernamental de Tbilisi, em 1977, e pelos pesquisadores Marcatto (2002), Sato (2003), Sariego (1995) e Mayhé-Nunes (1998).

Foi usado como instrumento de exploração do material um quadro (Quadro 1), que apresenta elementos de mapeamento. O primeiro elemento se constitui na presença (*), que indica que o material em questão apresenta de forma explicita a EA; o segundo elemento é a presença potencial (+), em que o assunto abordado permite a inclusão da EA por meio da mediação do professor; o terceiro elemento é a ausência (-), que representa que não há indícios de EA; e, o quarto elemento são as palavras-temas, na qual a pesquisadora retirou de cada parte analisada do material, no máximo, cinco palavras ou expressões que julgou estarem relacionadas com a EA. 
Quadro 1- Análise da Apostila em Relação à Educação Ambiental

\begin{tabular}{|c|c|c|c|c|c|}
\hline \multicolumn{6}{|c|}{ Análise da Apostila em Relação à Educação Ambiental } \\
\hline \multicolumn{2}{|r|}{ Ano: $6^{\circ}$} & \multicolumn{2}{|c|}{ Bimestre: } & \multicolumn{2}{|c|}{ Disciplina: } \\
\hline \multirow{2}{*}{\multicolumn{2}{|c|}{ UNIDADES }} & \multicolumn{4}{|c|}{ MAPEAMENTO: } \\
\hline & & $\begin{array}{c}\text { Presença } \\
(*)\end{array}$ & $\begin{array}{c}\text { Presença } \\
\text { Potencial (+) }\end{array}$ & Ausência (-) & $\begin{array}{c}\text { Palavras-Temas } \\
\text { (No máximo, cinco } \\
\text { palavras) }\end{array}$ \\
\hline \multirow{3}{*}{$\begin{array}{l}\frac{0}{0} \\
\frac{\pi}{0} \\
\frac{0}{5}\end{array}$} & Texto & & & & \\
\hline & $\begin{array}{c}\text { Textos } \\
\text { Complementares }\end{array}$ & & & & \\
\hline & Exercícios & & & & \\
\hline
\end{tabular}

Fonte: Organização dos autores, 2018

No período de tratamento dos resultados e da interpretação, foram analisados os dados obtidos com a tabela por meio da tabulação, demonstrando quantitativamente se há presença da EA no material didático utilizado pela rede municipal de ensino, no município de Lauro Müller.

\section{DISCUSSÃO E ANÁLISE DOS DADOS}

\subsection{Perfil dos participantes da pesquisa}

Todos os participantes da pesquisa são do sexo feminino e possuem idades entre 23 e 33 anos. Em relação ao nível de escolaridade, todas as pesquisadas possuem um curso de graduação concluído e voltado para a área de educação. Dessas professoras pesquisadas, três possuem pós-graduação lato sensu e uma está com o curso em andamento.

O tempo de trabalho no magistério indica que 50\% das pesquisadas possuem mais de 10 anos de experiência no ensino e o restante menos de cinco anos. As pesquisadas desenvolvem a docência em diferentes níveis de ensino: 
educação infantil, ensino fundamental anos iniciais e anos finais. Cabe destacar também a atuação dessas professoras, que estão inseridas na sua área de formação, mas eventualmente assumem disciplinas de outras áreas de conhecimento para compor a carga horária.

\subsection{Conceitos e práticas de Educação Ambiental de acordo com os professores}

Os resultados da pesquisa oriundos do grupo focal demonstram que as professoras reconhecem a relevância da EA, mas não conhecem sua definição de forma clara, citando problemas socioambientais em sentido amplo. Nas falas dos sujeitos da pesquisa, a EA é definida por meio de problemas relacionados à degradação ambiental, como destacou uma das professoras na sua fala: "... no município de Lauro Müller temos a degradação ambiental decorrente da extração do carvão mineral. Porque, se olharmos ao nosso redor, constatamos a marca negativa do homem ao longo da história. Fica assim a pergunta: o que vai ser dessa comunidade se continuarmos agindo assim?"

Como argumenta Guimarães (2000), um dos pontos fundamentais para o desenvolvimento da EA é o conhecimento de sua importância, de seus princípios, pois a EA articula conhecimentos que levam a formação de um cidadão crítico e atuante na sociedade e no ambiente em que está inserido. A Lei № 9.795 traz, em seu Art. $1^{\circ}$, o entendimento da EA, sendo considerado processo que constrói os valores da sociedade, conhecimentos, habilidades, atitudes e competências voltadas à conservação do meio ambiente, que é um direito comum, essencial para vida. (BRASIL, 1999).

O autor citado acima destaca que desenvolver EA requer incorporar diferentes atividades educativas na dimensão política, cultural, social e ética. Assim, torna-se possível a construção de novos valores e atitudes comprometidos com questões ambientais, ampliando os conhecimentos relativos aos seus problemas e soluções, com uma preocupação especial no que se refere à sustentabilidade. 
Usando a argumentação de Guimarães (2000), percebe-se que as professoras possuem um conceito vago sobre EA; no entanto, acreditam que a prática da EA é essencial para proporcionar um ambiente melhor, para um convívio coletivo digno, como ressalta uma das professoras “(...) tem que ir além do conteúdo apresentado no livro didático, tu tem que deixar um recado para os alunos. A EA é um dos grandes legados da escola".

Ao tratar da legislação que regulamenta a obrigatoriedade da EA em nível federal, estadual e municipal, constatou-se que as professoras desconhecem as leis que regulamentam e orientam a EA. As professoras reconheceram que a EA possui o caráter interdisciplinar, pois já ouviram essa menção nos meios de comunicação ou por compararem a EA com os temas transversais previstos na LDB, em especial ao tema meio ambiente. Somente uma das entrevistadas afirmou nunca ter tido contato com legislação pertinente à EA.

Ao discutir a EA como elemento importante para a educação formal e para o meio ambiente, o grupo destacou a ideia de continuidade, de senso crítico e de reforçar a consciência de que os recursos naturais são finitos. No entanto, não só por meio de conteúdos em sala de aula, mas por meio de exemplos, repetições de ideias e pequenas atitudes como: economizar água ou energia, ou seja, ações pontuais.

Durante a entrevista, uma das professoras discutiu um exemplo de sua infância, colocando em debate as atividades do "Dia da Árvore", quando as crianças plantavam várias espécies pela escola, mas, no dia seguinte, os mesmos alunos que plantaram acabavam destruindo ou arrancando as mudas. Nesse sentido, as professoras lançaram a importância de uma atividade continuada, já que ações isoladas não promovem mudanças. Concordando com Rosa (2013), muitas vezes, o que acontece no dia a dia das escolas é a promoção da EA apenas em datas comemorativas, como o Dia da Árvore, do Meio Ambiente ou da Água, ações esporádicas, sem continuidade, constituindo uma espécie de "dever" dos professores de Ciências e de Geografia. A legislação federal sobre os princípios 
da EA em se art. $4^{\circ}$ inciso $V$ determina a garantia de continuidade e permanência do processo educativo (BRASIL, 1999). Assim, a lei busca garantir que se desenvolva um projeto contínuo voltado a EA.

Quando questionadas sobre a participação ou elaboração de ações ou projetos de EA, nenhuma das professoras contribuiu. Voltaram a destacar ações isoladas, como recolhimento de pilhas voltaicas, óleo de cozinha, garrafas pet e a criação de brinquedos reciclados. Uma entrevistada ressaltou a gincana do Dia das Crianças realizada em 2014. Nessa gincana, os alunos, em uma das provas, construíram bonecos de material reciclado, usando caixas de papelão e de leite, garrafas pet e retalhos de EVA (Etil Vinil Acetato) (Figura 2).

\section{Figura 2 - Gincana: Dia das Crianças}

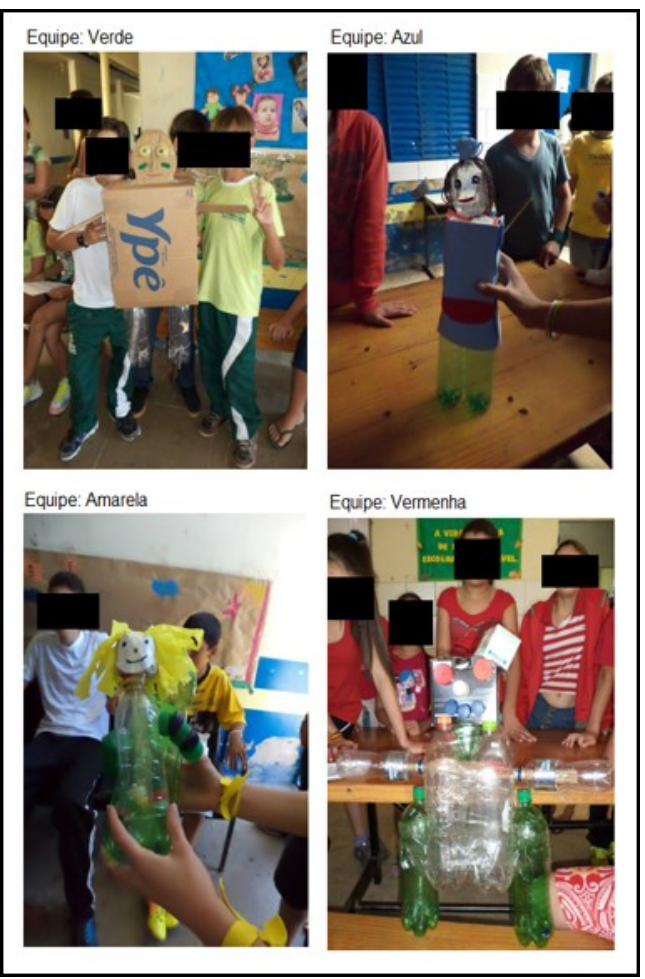

Fonte: Organização dos autores, 2018

Uma das professoras afirmou criar esculturas e instrumentos musicais com material reciclado, usando tecidos, esponjas, botões e latas, visto que sua disciplina permite essas atividades. Outra professora disse que já trabalhou com 
a produção de cartazes envolvendo temas da EA, como é demonstrado na Figura 4. As demais professoras disseram que a EA é desenvolvida por meio da discussão, partindo do conteúdo ministrado, mas não souberam exemplificar momentos em que isso ocorreu em sala de aula.

\section{Figura 3 - Atividades isoladas usando material reciclável}

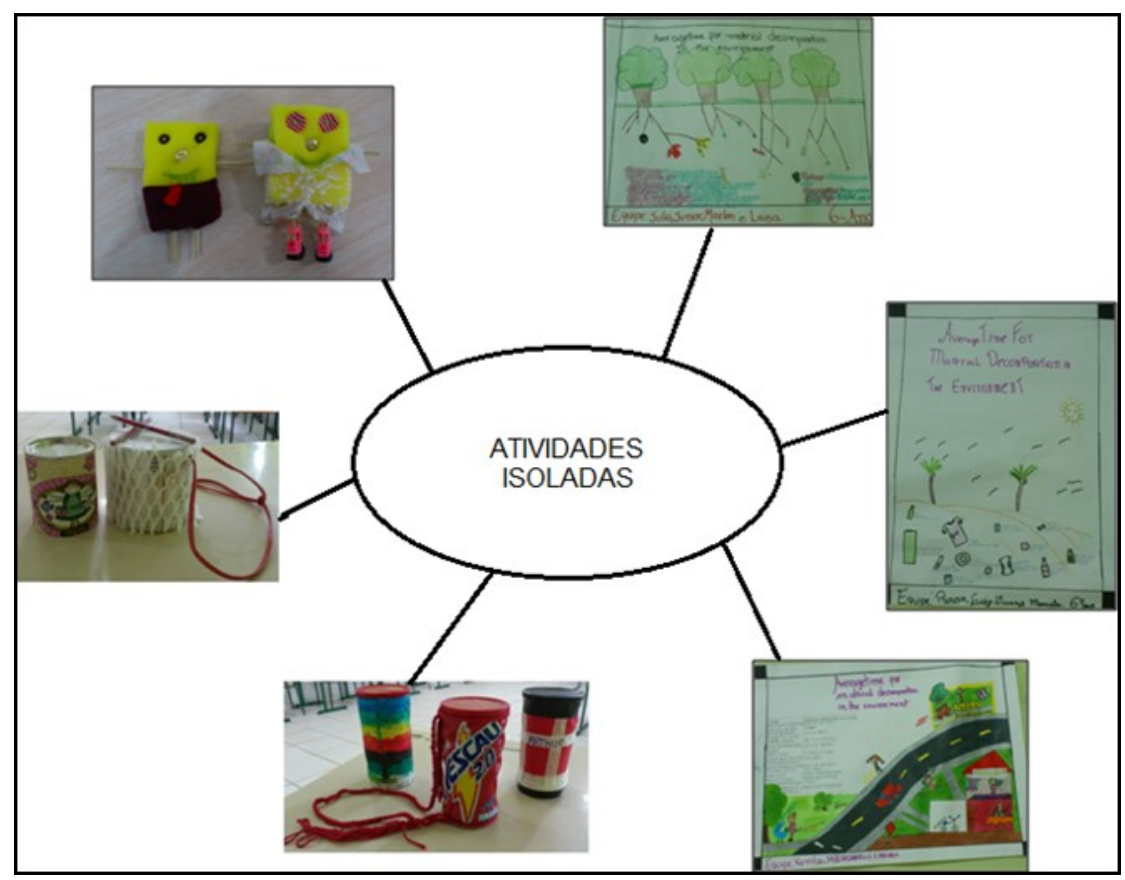

Fonte: Acervo particular dos autores (novembro de 2018)

As professoras mostram interesse no desenvolvimento da EA, mas suas falas evidenciaram que o conhecimento ainda é produzido de forma tradicional e fragmentada. Ou seja, cada professor em sua disciplina, em sua sala de aula, sem contato com os colegas ou com o exterior. A Figura 3 destaca um destes momentos, que se restringe ao trabalho com resíduos sólidos.

A ideia de reciclagem, de reutilização ou até mesmo de redução da geração de resíduos deve ser cultivada nos educandos; porém, atitudes isoladas não constroem o sentimento de sensibilização, pois não desperta em cada indivíduo a necessidade de promover a mudança. Segundo a Política Nacional de Educação 
Ambiental, um dos princípios da EA são o pluralismo de ideias e concepções pedagógicas, na perspectiva da inter, multi e transdisciplinar (BRASIL, 1999).

Sobre a elaboração e execução de projetos de EA, as professoras apresentaram as dificuldades em três pontos: falta de tempo, limites do sistema apostilado e falta de estrutura física e financeira na escola. Expuseram que não há tempo disponível para que professores se reúnam, planejem e elaborem projetos, mantendo, assim, o aprendizado fragmentado.

Segundo as professoras entrevistadas, o sistema apostilado limita as ações dos docentes, pois os alunos, pais e a própria Secretaria de Educação Municipal cobram o cumprimento da apostila em relação aos conteúdos e exercícios. Por outro lado, a falta de estrutura impede a realização de muitas ideias, pois isso implica estrutura física, custos com materiais e apoio financeiro. As professoras também afirmaram que faltam cursos de aperfeiçoamento para poder pôr em prática atividades de EA. Para mudar esta realidade a direção, professores, pais e alunos precisam organizar projetos que serão desenvolvidos durante o ano letivo.

Quando discutido sobre o material didático, uma das primeiras informações dadas pelas entrevistadas foi o tempo de uso do material, que é recente, as professoras têm de um até quatro anos de experiência. Várias foram as reclamações apontadas. Segundo as docentes, é um material que apresenta textos básicos, sendo observada a falta de referencial teórico consistente, a linguagem é difícil de ser interpretada e com discurso que não atende a realidade dos alunos. Deste modo, as apostilas apresentam os problemas também apontados por Sato (1995) em relação aos livros didáticos: a linguagem algumas vezes não é acessível ao educando, sendo de forma acadêmica, além de representar a ideologia da classe dominante e do sistema capitalista.

Outro ponto negativo em relação ao material didático citado pelas professoras são os conteúdos que se apresentam em nível nacional, ou seja, não evidenciam o ambiente local, a realidade da comunidade. Sato (2003) também 
ressalta essa dificuldade de se trabalhar questões local por meio dos livros didáticos, pois a grande maioria é produzida no eixo Rio - São Paulo. No entanto, a autora afirma que os professores devem por em prática sua formação, proporcionando essa ligação, ou seja, é o professor o mediador do conhecimento, que deve articular a conexão do global, regional para o local.

Segundo as docentes, a apostila conta com vários exercícios, mas que não apresentam uma ordem lógica e aparecem no meio do texto, muitas vezes, sem um contexto, uma relação direta com o assunto, como se fossem colocados de forma aleatória. Há exercícios muito fáceis e/ou muito difíceis para a idade dos alunos, sem uma estrutura que os explique devidamente. Os sujeitos da pesquisa gostariam de contar com atividades mais adequadas. A apostila apresenta material interativo e online, mas as docentes reclamam que materiais desse tipo não fazem parte da realidade dos alunos e muito menos da escola em questão, pois não há infraestrutura que possibilite seu uso. $\mathrm{Na}$ escola, faltam equipamentos, como computadores, data-show e acesso à internet que funcione de forma adequada para o bom aproveitamento do material.

Outro ponto discutido no grupo focal com relação ao material didático é a dependência que ele causa sobre a comunidade escolar, em especial os professores e alunos. Uma das professoras disse que, com o antigo livro didático distribuído pelo Governo Estadual de Santa Catarina, tinha mais autonomia para escolher os conteúdos que iria lecionar. Hoje, com a apostila tem que seguir o roteiro, pois sofrem uma cobrança. Por meio de experiência, relembram que, quando os livros didáticos foram implantados, houve uma cobrança semelhante por parte dos alunos e dos pais para seguir a sequência do livro, e que essa cobrança tende a diminuir com o passar do tempo.

Outra professora destacou que, em uma das reuniões pedagógicas de 2015, a diretora da unidade escolar liberou o uso da apostila nas aulas conforme o professor considerar melhor, mas ressaltando que todo o conteúdo deveria ser trabalhado. Dentro do grupo focal, apenas uma das professoras mencionou que 
o problema não é o material didático, mas sim a forma como os professores trabalham, já que os docentes têm autonomia para construir suas aulas, selecionar os conteúdos a serem trabalhados, mas ainda estão amarrados ao sistema de apostilas.

De forma geral, estes resultados corroboram com uma das críticas apresentadas por Britto em relação ao sistema apostilado, que está relacionada à redução da autonomia dos professores, que se transformam em "meros aplicadores do material didático" (2011, p. 15), já que devem seguir o roteiro apresentado no material. Por outro lado, para os gestores escolares e os familiares dos alunos, esta sequência do material permite um maior acompanhamento e controle das atividades de cada disciplina, que apresentam, de forma explícita, os objetivos referentes a cada aula. Neste sentido, este material não é tratado como um complemento, mas como um elemento obrigatório nas aulas, assim como o professor (BUNZEN, 2001). De forma semelhante, Freitag (1989) fez uma observação semelhante aos livros didáticos, enfatizando que estes materiais devem contribuir para o desenvolvimento da autonomia, da crítica ou da contra-ideologia, mas acabam se tornando o roteiro principal, até mesmo único do processo de ensino e aprendizagem.

Todas as participantes da pesquisa, com exceção de uma, afirmaram que a apostila traz poucos conteúdos relacionados à EA. Quando traz, segundo elas, é de forma indireta e as professoras têm que trazer materiais extras para dar conta do assunto. Apenas uma das professoras não concordou com essa ideia, afirmando que a apostila traz textos sobre EA de forma clara, pelo menos, em sua disciplina de Ciências. É importante afirmar que o material didático, muitas vezes, confunde o papel da EA, como mencionam Martins e Guimarães (2002), limitando-se a oferecer informações sobre o meio ambiente ou ecologia. Como ressaltam Pereira e Marcomin (2013), os professores de uma escola não podem depositar nos livros didáticos todo o compromisso da construção de uma EA, pois 
ele é apenas um veículo para a realização dessa missão. O professor deve ser crítico e criativo para envolver o conteúdo do material didático nos projetos de EA.

Quando tratado sobre os temas de ações e/ou projetos de EA que poderiam ser desenvolvidos com a comunidade escolar, as professoras elencaram os seguintes temas: resíduos sólidos, água, rios, mata ciliar, poluição do carvão, doenças (como o câncer, geradas pelo ambiente), energia eólica e solar, espaço rural e construção de horta. Rosa (2013) afirma que os assuntos a serem abordados em projetos de EA devem surgir naturalmente no decorrer das aulas, por meio do diálogo e do interesse dos alunos. A EA não precisa, necessariamente, abordar esses assuntos clássicos, como os citados pelas professoras, já que essas questões devem estar relacionadas com assuntos que fazem parte do cotidiano dos alunos. Nesse sentido, outros temas, que seriam pertinentes e relacionados à realidade escolar, como drogas, sexualidade, gravidez na adolescência, preconceito, respeito à religiosidade e com o próximo, poderiam ser tratados (ROSA, 2013).

Por meio do grupo focal, foi possível compreender que as professoras apresentam dificuldades para trabalhar a EA em suas aulas. Por um lado, as professoras afirmam ter liberdade de trabalhar os assuntos que consideram fundamentais para o momento. No entanto, falta o conhecimento do que é a EA, para saber planejar e por projetos em prática, pois o desconhecimento das leis, ou desse "conceito", provoca uma ideia confusa, faltando uma orientação mais assertiva para esses professores. O Art. $8^{\circ}$ legislação federal, Lei № 9.795 garante que a capacitação de professores por meio da difusão de conhecimentos, tecnologias e informações, preparando-os para disseminar a EA de uma forma coletiva e inter, multi e transdisciplinar (BRASIL, 1999). Assim, a educação segue fragmentada, com ideias isoladas, contrapondo o Art. $10^{\circ}$ da legislação federal, 
Lei $\mathrm{N}^{\circ}$ 9.795, segundo o qual a EA deve ser desenvolvida de forma contínua (BRASIL, 1999).

\subsection{0 material didático e a Educação Ambiental}

De forma geral, com base nos resultados da análise do material didático utilizado pela rede municipal de ensino, pode-se destacar que o mesmo apresenta conteúdos voltados à EA. Em alguns momentos de forma direta, ou seja, se identifica facilmente a EA, em outros de forma indireta e o professor consegue incluir a EA ao conteúdo ministrado. Em certos momentos, a apostila não apresenta indícios de EA, tornando mais difícil o trabalho do professor.

Após a exploração do material didático por meio de uma leitura criteriosa, houve o tratamento dos resultados, ou seja, as informações coletadas foram tabuladas sendo apresentadas na Tabela 1.

Por meio da Tabela 1, em função dos textos cabe destacar que a presença de conteúdos de EA ficou distribuída nas disciplinas de geografia seis ocorrências, história cinco e ciências quatro; sendo que nas disciplinas de artes e de língua portuguesa não são contempladas. Já a presença potencial aparece em todas as disciplinas e os maiores destaques foram história (17), geografia e língua inglesa (12 ocorrências cada). A escola é o local mais indicado para que se desenvolva a EA, mas como ressalta Reigota (1995), desde que se priorize a criatividade. No cenário escolar uma disciplina não possui mais valor que outra, como argumenta Reigota (1995), a ciência tem uma importante contribuição para com a EA; no entanto, não está mais autorizada do que a história, a geografia ou a língua portuguesa para exercer tal situação. 
Tabela 1 - Tabulação de dados - EA no material didático

Textos

\begin{tabular}{|c|c|c|c|c|c|}
\hline Disciplinas & Presença & $\begin{array}{l}\text { Presença } \\
\text { Potencial }\end{array}$ & Ausência & $\begin{array}{c}\text { Total de } \\
\text { Textos }\end{array}$ & $\begin{array}{c}\text { Total de } \\
\text { Unidades }\end{array}$ \\
\hline Matemática & 1 & 3 & 1 & 5 & 18 \\
\hline Língua & 0 & 3 & 2 & & 5 \\
\hline Portuguesa & & & & 5 & \\
\hline Língua & 1 & 5 & 6 & & 15 \\
\hline Inglesa & & & & 12 & \\
\hline História & 5 & 12 & 0 & 17 & 17 \\
\hline Geografia & 6 & 6 & 0 & 12 & 12 \\
\hline Ciências & 4 & 3 & 0 & 7 & 7 \\
\hline Artes & 0 & 4 & 0 & 4 & 4 \\
\hline
\end{tabular}

Textos Complementares

\begin{tabular}{|c|c|c|c|c|c|}
\hline Disciplinas & Presença & $\begin{array}{l}\text { Presença } \\
\text { Potencial }\end{array}$ & Ausência & $\begin{array}{l}\text { Total de Textos } \\
\text { Complementares }\end{array}$ & $\begin{array}{c}\text { Total de } \\
\text { Unidades }\end{array}$ \\
\hline Matemática & 2 & 4 & 8 & 14 & 18 \\
\hline Língua & 1 & 4 & 0 & & 5 \\
\hline Portuguesa & & & & 5 & \\
\hline Língua & 2 & 8 & 2 & & 15 \\
\hline Inglesa & & & & 12 & \\
\hline História & 2 & 10 & 2 & 14 & 17 \\
\hline Geografia & 5 & 4 & 0 & 9 & 12 \\
\hline Ciências & 4 & 3 & 0 & 7 & 7 \\
\hline Artes & 0 & 1 & 3 & 4 & 4 \\
\hline
\end{tabular}

Exercícios

\begin{tabular}{lccccc}
\hline Disciplinas & Presença & $\begin{array}{c}\text { Presença } \\
\text { Potencial }\end{array}$ & Ausência & $\begin{array}{c}\text { Total de } \\
\text { Exercícios }\end{array}$ & $\begin{array}{c}\text { Total de } \\
\text { Unidades } \\
18\end{array}$ \\
$\begin{array}{l}\text { Matemática } \\
\text { Língua }\end{array}$ & 5 & 12 & 1 & 18 & \\
$\begin{array}{l}\text { Portuguesa } \\
\text { Língua }\end{array}$ & 5 & 3 & 1 & & 5 \\
Inglesa & & 9 & 0 & & \\
História & 9 & 8 & 0 & 14 & 15 \\
Geografia & 7 & 5 & 0 & 17 & 17 \\
Ciências & 7 & 0 & 0 & 7 & 12 \\
Artes & 2 & 2 & 0 & 4 & 7 \\
\hline
\end{tabular}

Fonte: Organização dos autores, 2018 
Em maior ou menor porcentagem, presença ou presença potencial, todas as disciplinas apresentaram caminhos de se praticar a EA, com temas geradores, por exemplo, as palavras-temas presentes no conteúdo da disciplina Geografia: lugar, transformação da paisagem, cidade, identidade, sociedade, poluição e leis de águas. Utilizando a disciplina de geografia como exemplo, sugere-se que as estas palavras-temas podem proporcionar a EA, e os alunos poderiam trabalhar a história do município, o desenvolvimento da sociedade e da cidade. Saídas de campo poderiam ser incentivadas para o reconhecimento do lugar, da transformação da paisagem, da degradação dos recursos hídricos.

Apenas três disciplinas apresentaram a classificação ausência de conteúdo de EA em alguns de seus textos. Matemática possui uma ocorrência, a língua portuguesa apresentou duas e a língua inglesa se destacou com seis ocorrências.

Também foram analisados os textos complementares que são textos auxiliares para corroborar com o assunto principal da unidade. A Figura 5 foi desenvolvida com base na tabulação dos dados e demonstra a presença e a presença potencial, em porcentagem, entre as disciplinas analisadas.

Figura 4 - Presença e presença potencial de conteúdo de EA nos textos complementares do material didático

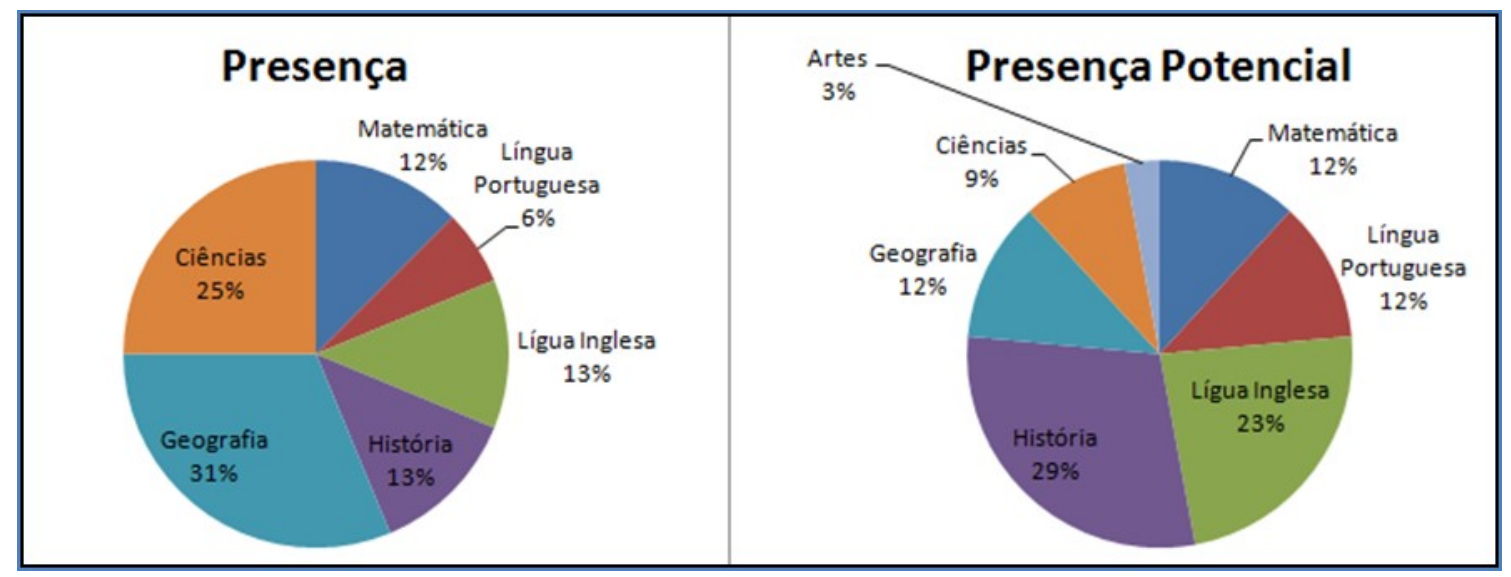

Fonte: Organização dos autores, 2018 
Com relação à presença de conteúdo de EA nos textos complementares, pode-se destacar a disciplina de geografia com $31 \%$ e a disciplina de ciência com 25\%. As outras disciplinas apresentam porcentagens menores, no entanto, consideráveis, entre $12 \%$ e 13\%, com exceção da disciplina de artes que não apresentou índices percentuais. Com relação à presença potencial de conteúdo, o destaque é atribuído a disciplina de história (29\%) e a disciplina de língua inglesa (23\%); em seguida, com um menor percentual, mas não menos importante, as disciplinas de geografia, língua portuguesa e matemática, cada uma com 12\%.

Os índices de conteúdo analisados nos textos complementares das apostilas mostram a potencialidade de se praticar EA, que são reafirmadas quando percebemos algumas palavras-temas entre as disciplinas: identificando os números na rua, comunicação, diversidade linguística, diferenças regionais, conto popular, propaganda, inglês a língua mais falada, fatos históricos, democracia, elementos culturais, êxodo rural, biodiversidade, furacão Catarina e aquecimento global. De modo geral, as apostilas apresentam fragmentos de EA em seus conteúdos e também na questão interdisciplinar. Como destaca Santomé (1998), essa questão abre a necessidade de utilização de criação de novos materiais didáticos, a fim de complementar as deficiências. Isso seria um desafio para a educação, para as instituições que promovem a pesquisa, para os professores e também para as editoras.

A Figura 5 foi desenvolvida a partir da tabulação dos dados e compreende a presença e a presença potencial, em porcentagem, com relação aos exercícios que constituem o material didático.

Os exercícios, de forma geral, incentivam desenvolver atividades de EA; para a classificação presença, a disciplina de história apresentou $25 \%$, as disciplinas de geografia e ciências 19\%. Em função da presença potencial, os destaques ficaram para a disciplina de matemática (31\%), língua inglesa (23\%) e história (20\%). As palavras- temas justificam as porcentagens do gráfico acima: 
diferenças culturais, organização social, comparando espaços, condições à vida e degradação ambiental. Em função dos exercícios da apostila, com relação à ausência de EA, somente as disciplinas de língua portuguesa e a matemática apresentaram uma ocorrência cada uma.

Figura 5 - Representação da presença e presença potencial de Educação Ambiental nos exercícios do material didático

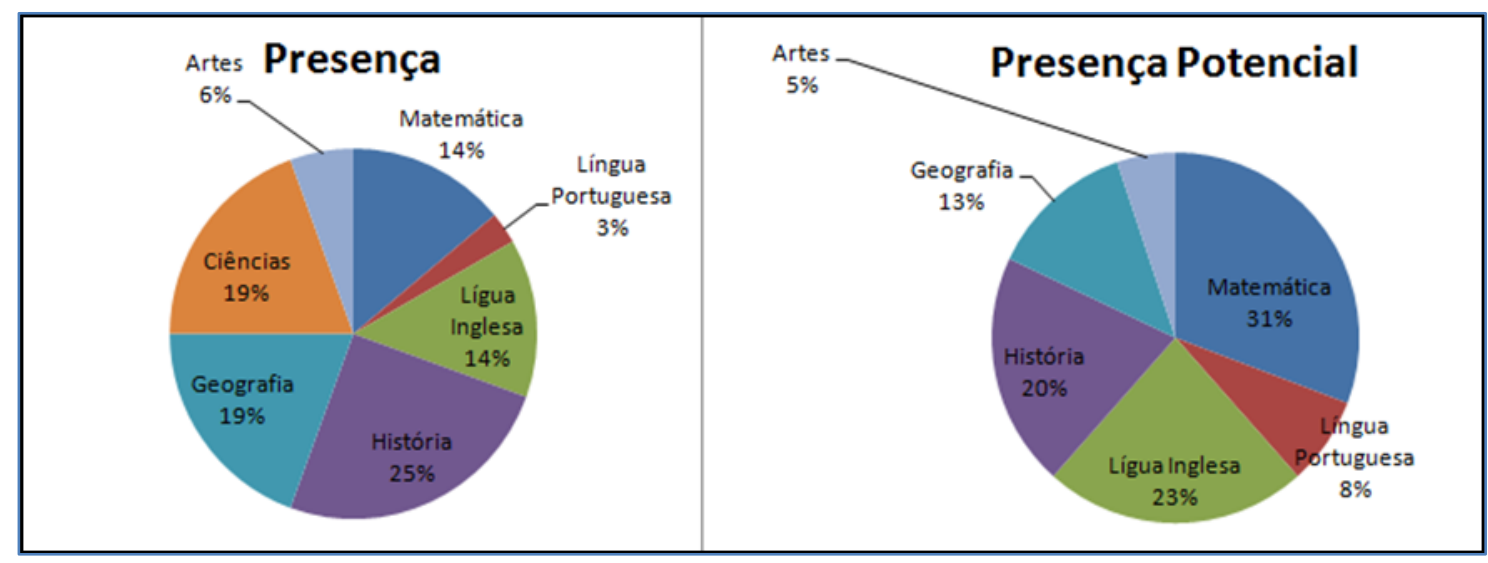

Fonte: Organização dos autores, 2018

Segundo Carvalho (2004), a EA só será "crítica e emancipatória" quando professores, editores, autores e gestores criarem um compromisso com um processo educativo integral e permanente que esteja ligado às questões ambientais. Para isso, concordando com Guimarães (2006), é necessária uma condição sinérgica entre todos que fazem parte do universo escolar e fora dele, ou seja, uma interação entre todos os participantes do ambiente escolar, potencializando o conhecimento, desenvolvendo atitudes e ações que possam transformar a sociedade atual.

\section{CONSIDERAÇÕES FINAIS}

A pesquisa demonstrou, por meio da análise de conteúdo, que as apostilas utilizadas pelo sexto ano das escolas públicas do município de Lauro Müller, 
apresentam conteúdos potenciais para a realização da EA, que superam concepções e práticas de uma abordagem naturalista. Esta constatação, no entanto, não garante que a EA seja uma realidade no cotidiano escolar, já que as professoras participantes da pesquisa apontaram conhecimentos vagos sobre a temática e sugerem que a EA apenas se efetiva em datas comemorativas alusivas ao meio ambiente e de forma que não rompe com as barreiras disciplinares.

Pode-se concluir que algumas das críticas anteriormente realizadas em relação aos livros didáticos são reproduzidas em relação às apostilas, como a dificuldade com a linguagem, a falta de conexões com a realidade local e a relação de dependência em relação a este material. Neste sentido, torna-se imprescindível o fortalecimento da autonomia destes profissionais, em um diálogo constante com toda a comunidade escolar, de modo que se compreenda o material didático como uma ferramenta, e não um guia inflexível e predeterminado do processo de ensino-aprendizagem. Aponta-se, ainda, a necessidade de formação continuada destes professores e da garantia de condições de trabalho que possibilitem a construção conjunta de alternativas de forma a integrar as áreas de conhecimento.

Por fim, a pesquisa com os resultados contribuiu para que a rede municipal de ensino de Lauro Müller possa trabalhar uma formação continuada que qualifique os professores com temas transversais e a partir destes organizar projetos e ou ações práticas a serem desenvolvidas durante o ano letivo.

Quando forem contratar a elaboração de novas apostilas devem incentivar a participação dos professores no processo de adesão, considerando três aspectos muito bem discutidos por Silva e Leite (2017): 1) investigar como os professores percebem a aderência de EA na rede municipal de ensino; 2) incentivar a participação em momentos de discussão antes de firmada a parceria; e, 3) coletar os sentimentos, expectativas e experiências dos docentes diante do que representa a apropriação do território e a questão do meio ambiente. 


\section{REFERÊNCIAS}

ADRIÃO, T.; GARCIA, T.; BORGHI, R.; ARELARO, L. Uma modalidade peculiar de privatização da educação pública: a aquisição de "sistemas de ensino" por municípios paulistas. Educ. Soc., Campinas, vol. 30, n. 108, p. 799-818, out. 2009.

BARDIN, L. Análise de conteúdo. Lisboa: Edições 70, 2004.

BEGO, A. A implantação de sistema apostilado de ensino e o trabalho docente: os problemas e as decisões de uma rede escolar pública municipal. Revista Brasileira de Estudos Pedagógicos, [s.I.], v. 98, n. 250, p.764-782, 18 jun. 2019. Instituto Nacional de Estudos e Pesquisas Educacionais Anisio Teixeira. http://dx.doi.org/10.24109/2176-6681.rbep.98i250.2695.

BOFF, L. A ética da vida. São Paulo. Letraviva, 1999.

BRASIL. Lei 9.394, de 20 de dezembro de 1996. Diretrizes e Bases da Educação Nacional. Disponível em: http://www.planalto.gov.br/ccivil_03/leis/19394.htm. Acesso em: 28 out. 2014.

BRASIL. Lei 9.795, de 27 abril de 1999. Política Nacional de Educação Ambiental. Disponível em: http://www.planalto.gov.br/ccivil_03/leis//9795.htm. Acesso em: 15 abr. 2014.

BRASIL. Proposta Curricular do Estado de Santa Catarina: formação integral na formação básica. Estado de Santa Catarina, Secretaria do Estado da Educação. 2014.

BRASIL. Resolução n², de 15 de junho de 2012. Diretrizes Curriculares Nacionais para Educação Ambiental. Disponível em: http://conferenciainfanto.mec.gov.br/images/pdf/diretrizes.pdf. Acesso em: 15 abr. 2014.

BRITTO, T. F. O Livro Didático, o Mercado Editorial e os Sistemas de Ensino Apostilados. Textos para discussão, n. 92. Centro de Estudos da Consultoria do Senado, 2011. Disponível em: http://www.abrale.com.br/wp-content/uploads/Livrodid\%C3\%A1 tico-o-mercado-editorial-e-os-sistemas-apostilados.pdf

BUNZEN, C. $\mathbf{O}$ antigo e o novo testamento: livro didático e apostila escolar. Ao pé da letra, 3.1:35-46, 2001

CARVALHO, I. C. de M. Educação ambiental: a formação do sujeito ecológico. 2. ed. São Paulo: Cortez, 2006. 
DIAS, G. F. Ecopercepção: um resumo didático dos desafios socioambientais. São Paulo: Gaia, 2004.

FAZENDA, I. C. A. Interdisciplinaridade: um projeto em parceria. São Paulo: Edições Loyola; 1999.

FREITAG, B; COSTA, W.F; MOTTA, V.R. O Livro Didático em Questão. São Paulo: Cortez: Autores Associados, 1989, 159p. (Coleção Educação Contemporânea)

GERALDI, J. W. Leitura: uma oferta de contrapalavras. Educar em Revista, Curitiba. PR: Ed. UFPR, n. 20, p. 77-85, 2002.

GIACOMINI, R. de M.; OTTO, C. SISTEMA DE ENSINO APOSTILADO: UM "CAVALO DE TROIA"?. Educação: Teoria e Prática, [s.l.], v. 27, n. 54, p.157-174, 27 abr. 2017. Departamento de Educação da Universidade Estadual Paulista - UNESP. http://dx.doi.org/10.18675/1981-8106.vol27.n54.p157-174.

GIL, A. C. Métodos e técnicas de pesquisa social. 5. ed. São Paulo: Atlas, 1999.

GRÜN, M. Ética e educação ambiental: a conexão necessária. Campinas: Papirus, 1996.

GUIMARÃES, M. Educação Ambiental: No consenso um embate? Campinas: Papirus, 2000.

LAURO MÜLLER (Município). Lei 1.507/2008, de 02 de abril de 2008. Política de Proteção, Conservação e Recuperação do Meio Ambiente. Disponível: Secretária Municipal de Agricultura e Meio Ambiente. Acesso: 21 jul. 2014.

LOPES, A. (Org.) Lauro Müller, a história. Orleans: Gráfica do lelo, 2008.

MARCATTO, C. Educação ambiental: conceitos e princípios. Belo Horizonte: FEAM, 2002.

MAYHÉ-NUNES, E. R. Educação Ambiental: princípios e objetivos. Revista de Educação, Brasília, n. 68, p. 19-28, abr./jun. 1988.

MORIN, E. Os sete saberes necessários à educação do futuro. São Paulo: Cortez; Brasília: UNESCO, 2002.

MOTTA, C. E. S. Indústria cultural e o sistema apostilado: a lógica do capitalismo. Caderno Cedes, Campinas, v. 21, n. 54, p.82-89, 2001. 
NASCIMENTO, D. do. Ferrovia e carvão: a Ferrovia Teresa Cristina no sul do Estado de Santa Catarina. In: FILHO, A. G. (Org.). Memória e cultura do carvão em Santa Catarina. Florianópolis: Cidade Futura, 2004.

PEREIRA, C. C.; MARCOMIN, F. E. Contribuições de Paulo Freire para a educação ambiental escolar. In: MARTINS, M. da C.; FROTA, P. R. de O. (Orgs.). Educação ambiental: a diversidade de um paradigma.Criciúma: UNESC, 2013. p. 167-188

PPP. Projeto Político Pedagógico. Lauro Müller: Escola Municipal Lígia Chaves Cabral, 2015.

ROSA, C. I. da. Contribuições de Paulo Freire para a educação ambiental escolar. In: MARTINS, M. da C.; FROTA, P. R. de O. (Orgs.). Educação ambiental: a diversidade de um paradigma. Criciúma: UNESC, 2013. p. 53-68

SANTA CATARINA (Estado). Lei 13.558, de 17 de novembro de 2005. Política Estadual de Educação Ambiental. Disponível em: www.sed.sc.gov.br/secretaria/. Acesso em: 15 abr. 2014.

SARIEGO, J. C. L. Emprego de revistas de divulgação científica como instrumento na Educação Ambiental. 1995. 195 f. Dissertação (Mestrado) - Universidade Estadual de Campinas, Campinas, 1995.

SATO, M. Educação Ambiental. São Carlos: Rima, 2003.

SEBRAE/SC. Santa Catarina em números: Lauro Müller. Florianópolis: SEBRAE/SC, 2010.

SHEIBE, L. F. Diagnóstico Preliminar da Qualidade Ambiental do Município de Lauro Müller, SC. Revista GEOSUL v.8, n¹0, ano VIII - p. 99 -107, $2^{\circ}$ semestre 1993.

SILVA, E. A. da; LEITE, Y. U. F. SISTEMAS APOSTILADOS DE ENSINO E A PARTICIPAÇÃO DO PROFESSORADO NO PROCESSO DE ADESÃO. In: CONGRESSO NACIONAL DE EDUCAÇÃO (EDUCERE), 13., 2017, Curitiba. Anais EDUCERE. Curitiba: Pucpr, 2017. p. 18892 - 18908. Disponível em: https://educere.pucpr.br/p1/anais.html. Acesso em: 16 set. 2017. 